\title{
The Impact of A Procedural Nursing Intervention to Prevent Deep Vein Thrombosis in Patients after Laparoscopic Distal Pancreatectomy and Splenectomy: A Retrospective Cohort Study
}

\section{Shan Xu ( $18827032308 @ 163 . c o m)$}

Tongji Medical College of Huazhong University of Science and Technology: Huazhong University of Science and Technology Tongji Medical College

\section{Li Xiao}

Tongji Medical College of Huazhong University of Science and Technology: Huazhong University of Science and Technology Tongji Medical College

\section{Min Wang}

Tongji Medical College of Huazhong University of Science and Technology: Huazhong University of Science and Technology Tongji Medical College

\section{Tieying Zeng}

Tongji Medical College of Huazhong University of Science and Technology: Huazhong University of Science and Technology Tongji Medical College https://orcid.org/0000-0001-5369-5342

\section{Research Article}

Keywords: Pancreatic cancer, Pancreatectomy, Splenectomy, Deep vein thrombosis, Patient satisfaction.

Posted Date: July 9th, 2021

DOI: https://doi.org/10.21203/rs.3.rs-608058/v1

License: (c) (i) This work is licensed under a Creative Commons Attribution 4.0 International License. Read Full License 


\section{Abstract}

Purpose The purpose of this study was to investigate the effect of procedural nursing intervention to prevent deep vein thrombosis (DVT) in patients after laparoscopic distal pancreatectomy and splenectomy (LDPS).

Methods We conducted a retrospective analysis of data from 80 patients with tumours of the pancreatic corpus or tail who underwent surgery at a high volume single centre. T-test and $c^{2}$ test were performed for data analysis. Study variables included incidence of DVT after LDPS, coagulation function indexes, and patient satisfaction.

Results For patients after LDPS, individuals receiving the procedural nursing intervention had a lower incidence of DVT compared to individuals receiving routine nursing care. There was no significant difference in Fibrinogen (FBI), D-Dimer(D-D), Activated Partial Thromboplastin Time (APTT), Prothrombin Time (PT), Thrombin Time (TT) between the two groups ( $>0.05)$. Platelet Count (PLT) among individuals receiving the procedural nursing intervention were significantly lower than those receiving routine nursing care. The procedural nursing interventions were associated with higher patient satisfaction compared to routine care.

Conclusions A procedural nursing intervention contributes to a lower incidence of DVT, lower PLT, higher satisfaction.

\section{Introduction}

Global Cancer Statistics 2018 summarized that in in 2018 the estimated number of new cases of pancreatic cancer was 458,918 , and the number of deaths was 432,242 globally [3]. L. Rahib et al. [22] projected pancreatic cancer to surpass breast, prostate, and colorectal cancers to become the second leading cause of cancer-related death by 2030 in the United States. Surgical resection is the only treatment that offers a potential cure for pancreatic cancer [17].

In the past decades, with the rapid development of laparoscopic surgical techniques, laparoscopic distal pancreatectomy (LDP) has become a widespread operation performed in the abdominal surgery $[18,19]$. LDP is recommended as the standard procedure for resecting benign, borderline, and malignant tumors of the pancreatic corpus or tail $[5,20]$. Because of the special anatomic relationship between the spleen and pancreas, LDP is usually performed with splenectomy, known as laparoscopic distal pancreatectomy splenectomy (LDPS) [28]. However, there are certain complications which may occur after LDPS, including pancreatic fistula, infection, post-surgical hemorrhage, overwhelming post-splenectomy infection (OPSI), thromboembolic event, etc.

Venous thromboembolism (VTE), manifests mainly as deep vein thrombosis (DVT) of the lower extremities and pulmonary embolism. The most substantial risk factors for the formation of VTE are certain types of surgery and malignancies [23]. Patients undergoing surgery are at an increased risk of 
VTE, which often results in poor postoperative recovery and endangerment of the patient's life $[6,10]$. European and American data showed that the incidence of DVT in patients after general surgery was 10$40 \%$ when there was no preventive measures against DVT [7]. Studies have revealed that the risk of DVT increased after splenectomy, liver surgery and pancreatic surgery $[8,24]$. As a potentially life-threatening complication, DVT after LDPS continues to challenge nurses daily. Therefore, shifting the assessment and interventions to prevention is one key point of clinical nursing work. In our study, 80 patients who underwent LDPS from January 2016 to December 2019 were selected to investigate the impact of procedural nursing intervention on the incidence of DVT after LDPS.

\section{Methodology}

The purpose of this study was to investigate the effect of procedural nursing intervention to prevent deep vein thrombosis (DVT) in patients after laparoscopic distal pancreatectomy and splenectomy (LDPS).

A retrospective cohort study design was used. The Strengthening the Reporting of Observational Studies in Epidemiology (STROBE) EQUATOR checklist was used for this study (see Supplementary Table 1). This retrospective study was conducted in the department of biliary and pancreatic surgery, totaling 200 beds at our hospital. After receiving institutional review board approval for a retrospective cohort study, a review of the medical records of patients after LDPS from January 1, 2016 to December 31, 2019 was undertaken. All patients were identified by being assigned a code.

The inclusion criteria were (1) patients were aged from 18 to 70 years old; (2) patients received LDPS. Patients were excluded if they (1) had a previous history of lower limb DVT or had other vascular diseases in lower limbs; (2) had severe heart disease or myocardial infarction; (3) had a cerebrovascular disease or hemorrhagic tendency; (4) had obvious abnormal coagulation indicators before surgery; (5) taken anticoagulants or antiplatelet medications one month before surgery.

A total of 80 patients presenting after LDPS, were chart audited. Considering that procedural nursing interventions against perioperative thrombosis were carried out since January 1, 2018 in our hospital, 40 patients who underwent LDPS and received routine care from January 1, 2016 to December 31, 2017 were selected as the control group, and another 40 patients who underwent LDPS and received a procedural nursing intervention from January 1, 2018 to December 31, 2019 were selected as the observation group.

The Caprini scale was built into the electronic medical record in January 2018. In the electronic medical record, a DVT risk assessment was completed the by the clinical nurses after the patient underwent the operation. Depending on the total scale score, patients were categorized as at low, medium or high risk for DVT consequence. The clinical nurses were then alerted of different risk level for each patient. Within each of these categories, targeted interventions were defined (Table 1).

If the score was a high risk, it was required that the patients signed a notification form for preventing DVT; red warning signs that read " Deep Vein Thrombosis Prevention " were hung on the patient's bedside. 
Appropriate DVT prevention measures needed for each patient were included in the priority nursing handover. Detailed intervention measures undertaken are as follows.

\section{Health education:}

Multi-channel health education was provided throughout the hospital stay. Patient education pamphlets and DVT precautionary lists were developed and were placed at the patient's bedside. Videos of postoperative lower extremity functional exercises were created and played every morning. Activity maps were created to engage patients in effective prevention methods. Some practical and acceptable advice was posted regularly via the public WeChat account. For example, some of the advice posted were "to avoid smoking and alcohol consumption, ensure that you get enough sleep, limit sugar and salt intake" among many others.

\section{Basic prevention:}

When the patients were in bed, soft pillows or trapezoidal pillows (about $25^{\circ}$ ) were placed under their extremities. Their upper body was raised to a $15^{\circ}$ angle, knee joints were flexed at a $15^{\circ}$ angle and lower limbs raised to $15-30^{\circ}$ to fully relax the muscles. Patients were encouraged to perform functional exercises early, to turn over, take deep breaths, to cough, increase diaphragm movement and promote blood flow. Furthermore, postsurgical patients were instructed to perform lower extremity exercises to include plantar flexion, dorsal extension, rotation of the ankle; isometric contraction of the quadricep and non-weight-bearing straight leg lifting of the quadriceps. They were instructed to perform these exercises in groups of 20 to 30 patients for 3 to 4 times a day. Exercise time and frequency were adjusted according to the patient's activity tolerance.

\section{Physical prevention:}

Intermittent pneumatic compression devices (IPC) were applied during the periods of inactivity for 30 minutes each time, once in the morning and afternoon. IPC inflates and deflates multi-chamber balloons in an orderly manner to squeeze the limbs from the distal end to the proximal end in an orderly manner to form circulatory pressure, promoting blood flow, slowing venous stasis, and reducing the occurrence of DVT [21].

\section{Drug prevention:}

High-risk patients used low-molecular-weight heparin sodium following the doctor's order. Both the US ACCP [8] guidelines and the UK NICE [4] guidelines to prevent DVT mentioned that under the conditions where anticoagulants could be used, they recommended it to be combined with some physical activity/ambulation to reduce the incidence of DVT.

The data was extracted retrospectively from the medical records of the patients. Data was collected from January 1, 2016 to December 31, 2019 (a total of 48 months). We completed the following data collection on the participants (1) baseline sample characteristics (age, gender, comorbidities), (2) the incidence of DVT, (3) the coagulation function indexes (FIB, DD, PLT, APTT, PT, TT), (4) nursing 
satisfaction. All statistical analyses were performed using SPSS 23.0. The measurement data was expressed as mean \pm standard deviation and analyzed by t-test; the count data was expressed as frequency or percentage, and the $\chi^{2}$ test was used. Differences were considered statistically significant when $\mathrm{P}<0.05$.

\section{Results}

\section{Baseline sample characteristics}

Table 2 details the baseline sample characteristics. For the entire group, the mean age of the participants were $48.53 \pm 16.30$ years. Mean age of the control group and observation group were $44.88 \pm 15.97$ years and $51.03 \pm 16.26$ years, respectively. Differences in age between the two groups were insignificant $(p=0.14)$. Of the 80 participants, 38 were male, and 42 were female, with little difference between groups $(p=0.654)$. Comorbidities were also considered in our study with 13 participants having hypertension, and 6 having diabetes, but no significant difference was found between groups ( $p=0.363$ for hypertension, $p=0.692$ for diabetes). Patients with malignant tumors may have had changes in their hemodynamics, which urged us to take pathology into account. 17 of the 80 patients have a malignant tumor, with 7 from control group and 10 from the observation group. No significant difference was found between groups $(p=0.412)$. Basic clinical data of patients in the two groups were balanced and comparable $(P>0.05)$ (Table 2).

\section{Incidence of DVT}

The diagnosis of DVT was determined by the symptoms and signs of DVT, D-D and color Doppler ultrasound (Figure 1). The diagnostic criteria were in accordance with the standards set by the Peripheral Vascular Disease Committee of the Chinese Society of Integrative Medicine [12]. The incidence of DVT seven days after the operation in the observation group was lower than that in the control group $(2.5 \%$ (1/40) vs $20 \%(8 / 40), \mathrm{P}<0.05)$ (Table 3 ).

\section{Coagulation function indexes}

There was no significant difference in FBI, D-D, APTT, PT, TT between the two groups $(P>0.05)$. The PLT level of the patients in the observation group (356.6 191.34$)$ was significantly lower than that of the control group $(450.7 \pm 165.10, \mathrm{P}<0.05)$ (Table 3$)$.

\section{Nursing satisfaction}

In light of our hospital's self-made nursing satisfaction rating scale, patients were characterized as dissatisfied, satisfied or very satisfied. Overall satisfaction rate $=$ (very satisfied + satisfied) $/$ total number of cases $\times 100 \%$. As is shown in Table 4 , the nursing satisfaction score of the patients in the observation group was significantly higher than that of the control group $(P<0.05)$ (Table 4). 


\section{Discussion}

The aims of this study were to investigate the effects of procedural nursing intervention on patient outcome and to identify the preliminary results of evidence-based clinical practice. The results demonstrate that appropriate assessment and effective intervention based on risk level can help to decrease the prevalence of DVT after LDPS. In addition, nurses are in a critical position to implement procedural care and help improve patient care related to the prevention of DVT.

There are three factors that contribute to DVT: venous stasis, vessel wall injury and hypercoagulability, which is known as the Virchow's triad [2, 16]. Also, C. N. Gutt et al. [9]supported the notion that surgical patient accumulated more risks than non-surgical patients from every side of the Virchow triad. The Society of American Gastrointestinal and Endoscopic Surgeons (SAG-ES) laparoscopic surgery DVT prevention guidelines believed that all laparoscopic surgery could cause blood hypercoagulability in varying degrees [26]. Additionally, studies have reported that about $75 \%$ of patients after splenic resection developed thrombocytosis, and about $1.6-55 \%$ of patients due to their inability or unwillingness to ambulate participate in lower extremity exercise among many other negative practices caused thrombosis [27]. The above literature show that patients after LDPS present a high incidence of DVT. Similar to previous studies, we observed an increased incidence of postoperative DVT in the control group when patients were not under monitoring and management. Many Euro-American guidelines recommended that verified best approaches should be given to patients with different DVT risk stratification $[4,8]$. Furthermore, Chinese General Surgery Perioperative Thrombosis Prevention and Management Guidelines identified that preventive measures for DVT in general surgery patients [14]. The American Society of Clinical Oncology VTE Guideline Pane demonstrated that patients undergoing major surgery for malignant disease should be considered for pharmacologic thromboprophylaxis [15]. Due to the understanding of the guidelines and the integration of evidence into clinical practice, a systematic and thoughtful protocol for DVT prevention was developed, which could account for the lower incidence of DVT in the observation group.

It is well known that DVT is closely related to coagulation. Participants' coagulation parameters (including FBI, DD, PLT, APTT, PT, TT) were also observed and recorded in the study. Our results suggested that $\mathrm{FBI}, \mathrm{D}-\mathrm{D}, \mathrm{APTT}, \mathrm{PT}$ and TT in two groups were different, but there was no significant difference $(\mathrm{P}>$ 0.05); the PLT count of the patients in the observation group was smaller than that in the control group. Several studies provide the evidence that high PLT is associated with the occurrence of VTE $[13,25,29]$. From the perspective of PLT level, the procedural nursing intervention was beneficial to those who underwent LDPS.

Patient satisfaction is a sensitive measure of a well-functioning health service system in modern healthcare [11]. As a critical outcome quality indicator, satisfaction was also taken into account in the current study. The overall satisfaction of the observation group (97.5\%) within this study was significantly higher than that of the control group (80.0\%), demonstrating that patients thought procedural care was positive and effective at preventing DVT after LDPS. In the implementation of 
procedural care, clear, high-quality information and education were provided to the patients.

Consequently, they had an in-depth understanding of DVT and recognized that they were susceptible to potentially life-threatening complications. Furthermore, procedural nursing interventions have proven to be an acceptable way to allow patients to engage in their rehabilitation after major surgery; which may be the mechanism behind improved satisfaction. Our findings are synonymous with those of $\mathrm{J}$. Andrawis et al. [1] who confirmed after his study that satisfaction scores were higher when patients were involved in their health promotion.

\section{Limitations}

The findings of the present study should be interpreted considering certain limitations. First, a small sample was used to conduct the study, which reduced the statistical strength of some important findings. Second, as a chart review study, the quality of the information is dependent on coherent and accurate medical charting. A third limitation of our study was that several unobserved confounders (e.g., postoperative bedtime) were not adequately documented in the charts. The lack of these additional data may or may not have an impact on the accuracy of clinical outcomes. To counter these limitations, a prospective study design with robustly calculated sample size would add further valuable insights on the topic.

\section{Conclusions}

Although the prevention of DVT after LDPS remains a challenge for healthcare providers, we have strived to integrate evidence from research and guidelines into nursing practice to create procedural care. It is evident that procedural care provides significant benefits to the patient. Procedural nursing measures include health education, primary prevention, physical prevention and drug prevention. Obviously, with the implementation of the comprehensive and targeted DVT prevention interventions, DVT risks could be assessed and managed promptly, resulting in lower incidences of DVT, normal PLT levels and higher patient satisfaction. Overall, our study upholds the reliability of procedural nursing interventions.

\section{Declarations}

\section{Acknowledgements}

The authors gratefully acknowledge Yuhui Liu, MD, for project design.

Funding: This research was funded by the National Natural Science Foundation of China (81773160).

Conflicts of interest/Competing interests: None

Availability of data and material: N/A

Code availability: N/A 
Authors' contributions: The study was designed by Shan Xu and Tieying Zeng. Data collection and analysis were performed by Shan Xu and Li Xiao. Manuscript was written by Shan Xu and Min Wang. Tieying Zeng supervised the study. All authors read and approved the final manuscript.

Ethics approval: This study was approved by institutional review board of Affiliated Tongji Hospital, Tongji Medical College, Huazhong University of Science and Technology.

Consent to participate: N/A

Consent for publication: N/A

\section{References}

1. Andrawis J, Akhavan S, Chan V, Lehil M, Pong D, Bozic KJ (2015) Higher Preoperative Patient Activation Associated With Better Patient-reported Outcomes After Total Joint Arthroplasty. Clin Orthop Relat Res 473: 2688-2697. https://doi.org/10.1007/s11999-015-4247-4

2. Bovill EG, van der Vliet A (2011) Venous Valvular Stasis-Associated Hypoxia and Thrombosis: What Is the Link? Annual Review of Physiology 73: 527-545. https://doi.org/10.1146/annurev-physiol-012110142305

3. Bray F, Ferlay J, Soerjomataram I, Siegel RL, Torre LA, Jemal A (2018) Global cancer statistics 2018: GLOBOCAN estimates of incidence and mortality worldwide for 36 cancers in 185 countries. CA: a cancer journal for clinicians 68: 394-424. https://doi.org/10.3322/caac.21492

4. Chong LY, Fenu E, Stansby G, Hodgkinson S (2012) Management of venous thromboembolic diseases and the role of thrombophilia testing: summary of NICE guidance. Bmj 344: e3979-e3979.

https://doi.org/10.1136/bmj.e3979

5. Damoli I, Butturini G, Ramera M, Paiella S, Marchegiani G, Bassi C (2015) Minimally invasive pancreatic surgery - a review. Wideochir Inne Tech Maloinwazyjne 10: 141-149.

https://doi.org/10.5114/wiitm.2015.52705

6. Erem HH, Aytac E (2017) The Use of Surgical Care Improvement Projects in Prevention of Venous Thromboembolism. In: Islam MS (ed) Thrombosis and Embolism: from Research to Clinical Practice: Volume 1. Springer International Publishing, Cham, pp. 15-22.

7. Geerts WH, Bergqvist D, Pineo GF, Heit JA, Samama CM, Lassen MR, Colwell CW (2008) Prevention of venous thromboembolism: American College of Chest Physicians Evidence-Based Clinical Practice Guidelines (8th Edition). Chest 133: 381S-453S. https://doi.org/10.1378/chest.08-0656

8. Gould MK, Garcia DA, Wren SM, Karanicolas PJ, Arcelus JI, Heit JA, Samama CM (2012) Prevention of VTE in nonorthopedic surgical patients: Antithrombotic Therapy and Prevention of Thrombosis, 9th ed: 
American College of Chest Physicians Evidence-Based Clinical Practice Guidelines. Chest 141: e227Se277S. https://doi.org/10.1378/chest.11-2297

9. Gutt CN, Oniu T, Wolkener F, Mehrabi A, Mistry S, Buchler MW (2005) Prophylaxis and treatment of deep vein thrombosis in general surgery. Am J Surg 189: 14-22. https://doi.org/10.1016/j.amjsurg.2004.04.009

10. Hansrani V, Khanbhai M, McCollum C (2017) The Prevention of Venous Thromboembolism in Surgical Patients. In: Islam MS (ed) Thrombosis and Embolism: from Research to Clinical Practice: Volume 1. Springer International Publishing, Cham, pp. 1-8.

11. Heidegger T, Saal D, Nubling M (2013) Patient satisfaction with anaesthesia - Part 1: satisfaction as part of outcome - and what satisfies patients. Anaesthesia 68: 1165-1172. https://doi.org/10.1111/anae.12347

12. Hou Yufen LZ (2016) Criteria for the Diagnosis and Efficacy of Deep Vein Thrombosis in the Lower Extremities (2015 Revision). Chinese Journal of Surgery of Integrated Traditional and Western Medicine 22: 520-521.(in Chinese).

13. Khorana AA, Francis CW, Culakova E, Lyman GH (2005) Risk factors for chemotherapy-associated venous thromboembolism in a prospective observational study. Cancer 104: 2822-2829. https://doi.org/10.1002/cncr.21496

14. LIU Fenglin ZT (2016) Guidelines for the Prevention and Management of Thrombosis in General Surgery in China. Chinese Journal of Surgery 54: 321-327. (in Chinese).

15. Lyman GH, Khorana AA, Falanga A, Clarke-Pearson D, Flowers C, Jahanzeb M, Kakkar A, Kuderer NM, Levine MN, Liebman H, Mendelson D, Raskob G, Somerfield MR, Thodiyil P, Trent D, Francis CW, American Society of Clinical O (2007) American Society of Clinical Oncology guideline: recommendations for venous thromboembolism prophylaxis and treatment in patients with cancer. J Clin Oncol 25: 5490-5505. https://doi.org/10.1200/JCO.2007.14.1283

16. Martinelli I, Bucciarelli P, Mannucci PM (2010) Thrombotic risk factors: basic pathophysiology. Crit Care Med 38: S3-9. https://doi.org/10.1097/CCM.0b013e3181c9cbd9

17. McGuigan A, Kelly P, Turkington RC, Jones C, Coleman HG, McCain RS (2018) Pancreatic cancer: A review of clinical diagnosis, epidemiology, treatment and outcomes. World J Gastroenterol 24: 48464861. https://doi.org/10.3748/wjg.v24.i43.4846

18. Mehta SS, Doumane G, Mura T, Nocca D, Fabre J-M (2011) Laparoscopic versus open distal pancreatectomy: a single-institution case-control study. Surgical Endoscopy 26: 402-407. https://doi.org/10.1007/s00464-011-1887-7

19. Melotti G, Butturini G, Piccoli M, Casetti L, Bassi C, Mullineris B, Lazzaretti MG, Pederzoli P (2007) Laparoscopic Distal Pancreatectomy. Annals of Surgery 246: 77-82. 
https://doi.org/10.1097/01.sla.0000258607.17194.2b

20. Parikh PY, Lillemoe KD (2015) Surgical management of pancreatic cancer-distal pancreatectomy. Semin Oncol 42: 110-122. https://doi.org/10.1053/j.seminoncol.2014.12.010

21. Pour AE, Keshavarzi NR, Purtill JJ, Sharkey PF, Parvizi J (2013) Is venous foot pump effective in prevention of thromboembolic disease after joint arthroplasty: a meta-analysis. J Arthroplasty 28: 410417. https://doi.org/10.1016/j.arth.2012.08.003

22. Rahib L, Smith BD, Aizenberg R, Rosenzweig AB, Fleshman JM, Matrisian LM (2014) Projecting cancer incidence and deaths to 2030: the unexpected burden of thyroid, liver, and pancreas cancers in the United States. Cancer Res 74: 2913-2921. https://doi.org/10.1158/0008-5472.CAN-14-0155

23. Rosendaal FR (2016) Causes of venous thrombosis. Thromb J 14: 24. https://doi.org/10.1186/s12959-016-0108-y

24. Shah DR, Wang H, Bold RJ, Yang X, Martinez SR, Yang AD, Khatri VP, Wisner DH, Canter RJ (2013) Nomograms to predict risk of in-hospital and post-discharge venous thromboembolism after abdominal and thoracic surgery: an American College of Surgeons National Surgical Quality Improvement Program analysis. J Surg Res 183: 462-471. https://doi.org/10.1016/j.jss.2012.12.016

25. Simanek R, Vormittag R, Ay C, Alguel G, Dunkler D, Schwarzinger I, Steger G, Jaeger U, Zielinski C, Pabinger I (2010) High platelet count associated with venous thromboembolism in cancer patients: results from the Vienna Cancer and Thrombosis Study (CATS). J Thromb Haemost 8: 114-120. https://doi.org/10.1111/j.1538-7836.2009.03680.x

26. Society of American G, Endoscopic Surgeons Guidelines C (2007) Guidelines for deep venous thrombosis prophylaxis during laparoscopic surgery. Surg Endosc 21: 1007-1009. https://doi.org/10.1007/s00464-007-9340-7

27. Sun LM, Chen HJ, Jeng LB, Li TC, Wu SC, Kao CH (2015) Splenectomy and increased subsequent cancer risk: a nationwide population-based cohort study. Am J Surg 210: 243-251. https://doi.org/10.1016/j.amjsurg.2015.01.017

28. Wang K, Fan Y (2017) Minimally Invasive Distal Pancreatectomy: Review of the English Literature. Journal of Laparoendoscopic \& Advanced Surgical Techniques 27: 134-140. https://doi.org/10.1089/lap.2016.0132

29. Zakai NA, Wright J, Cushman M (2004) Risk factors for venous thrombosis in medical inpatients: validation of a thrombosis risk score. J Thromb Haemost 2: 2156-2161. https://doi.org/10.1111/j.15387836.2004.00991.x

\section{Tables}




\section{Table 1}

DVT Risk Level and Prevention Program

\begin{tabular}{|lll|}
\hline Score & Risk level & Prevention program \\
$\begin{array}{l}1-2 \\
\text { points }\end{array}$ & Low risk & Health education + basic prevention \\
\hline $\begin{array}{l}3-4 \\
\text { points }\end{array}$ & $\begin{array}{l}\text { Medium } \\
\text { risk }\end{array}$ & Health education + basic prevention + physical prevention \\
$\begin{array}{l}\geq 5 \\
\text { points }\end{array}$ & High risk & $\begin{array}{l}\text { Health education + basic prevention +physical prevention }+ \text { drug } \\
\text { prevention }\end{array}$ \\
\hline
\end{tabular}

\section{Table 2}

Baseline Sample Characteristics

\begin{tabular}{|lllll|}
\hline & Total & Control & Observation & \\
\hline & $(\mathrm{N}=80)$ & $(\mathrm{n}=40)$ & $(\mathrm{n}=40)$ & \\
\hline Characteristics & $\mathrm{n}$ & $\mathrm{n}$ & $\mathrm{n}$ & $\mathrm{p}$ \\
\hline Age & $48.5 \pm 16.30$ & $44.88 \pm 15.97$ & $51.03 \pm 16.26$ & 0.140 \\
\hline Gender & & & & 0.654 \\
\hline Male & 38 & 18 & 20 & \\
\hline Female & 42 & 22 & 20 & \\
\hline Comorbidities & & & & 0.363 \\
\hline Hypertension & 13 & 8 & 5 & 1.000 \\
\hline $\begin{array}{l}\text { Diabetes } \\
\text { Tumor }\end{array}$ & 6 & 3 & 3 & 0.412 \\
Benign & 63 & 33 & 30 & \\
Malignant & 17 & 7 & 10 & \\
\hline
\end{tabular}

\section{Table 3}

Comparison of Coagulation Function Between Two Groups of Patients $(\mathrm{N}=40)$ 


\begin{tabular}{|lllll|}
\hline & Normal range & Control & Observation & P-value \\
\hline FBI $₫ \mathrm{~g} / \mathrm{L} \rrbracket$ & $2.00-4.00$ & $4.52 \pm 1.41$ & $4.68 \pm 1.66$ & 0.687 \\
\hline $\mathrm{D}-\mathrm{D}(\mathrm{ug} / \mathrm{mL})$ & $<0.5$ & $3.71 \pm 2.81$ & $3.48 \pm 2.29$ & 0.722 \\
\hline PLT $\left(\times 10^{9}\right)$ & $125.0-350.0$ & $450.7 \pm 165.10$ & $356.6 \pm 191.34$ & 0.046 \\
\hline APTT(s) & $29.0-42.0$ & $40.1 \pm 5.37$ & $38.1 \pm 5.05$ & 0.130 \\
\hline PT(s) & $11.5-14.5$ & $14.8 \pm 1.54$ & $14.6 \pm 1.30$ & 0.608 \\
\hline TT(s) & $14.0-19.0$ & $15.4 \pm 1.09$ & $15.8 \pm 1.48$ & 0.357 \\
\hline Incidence of DVT & & 8 & 1 & 0.034 \\
\hline
\end{tabular}

\section{Table 4}

Comparison of Nursing Satisfaction Between the Two Groups

\begin{tabular}{|c|c|c|c|}
\hline & $\begin{array}{l}\text { Control } \\
(n=40)\end{array}$ & $\begin{array}{l}\text { Observation } \\
(n=40)\end{array}$ & \\
\hline Variable & $\mathrm{n}(\mathrm{n} / 40 \times 100)$ & $n(n / 40 \times 100)$ & $\mathrm{P}$ \\
\hline Very satisfied & $16 \varangle 40.00 \rrbracket$ & $25 \llbracket 62.50 \rrbracket$ & 0.116 \\
\hline Satisfied & $16 \varangle 40.00 \rrbracket$ & $14 \llbracket 35.00 \rrbracket$ & 0.644 \\
\hline Dissatisfied & $8 \llbracket 20.00 \rrbracket$ & $1 \rrbracket 2.50 \rrbracket$ & 0.034 \\
\hline Overall satisfaction & $32 \bowtie 80.00 \rrbracket$ & $39 \rrbracket 97.50 \rrbracket$ & 0.034 \\
\hline
\end{tabular}

\section{Supplementary File}

Supplementary Table 1 is not available with this version

\section{Figures}




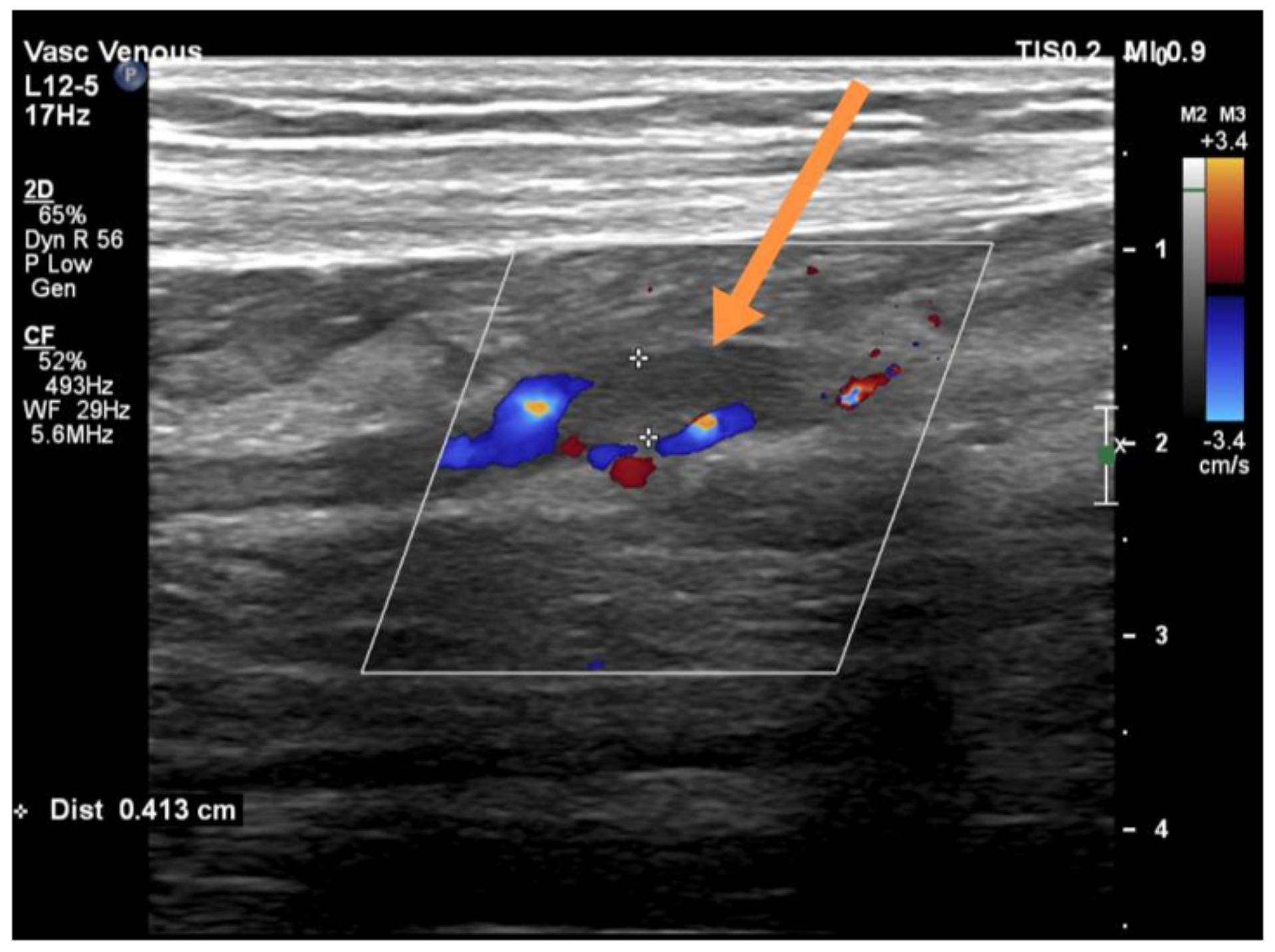

\section{Figure 1}

The result of color Doppler ultrasound (CDU) in patient with DVT in control group. The arrow indicates blood flow filling defect in intermuscular vein. 